\title{
Orígenes clásicos del relativismo político contemporáneo*
}

Fecha de envío: 20 de abril de 2020

Fecha de evaluación: 24 de abril de 2020

Fecha de aprobación: 27 de abril de 2020

\author{
Rafael Esteban Gutiérrez Lopera**
}

\section{Resumen}

Se ofrece una caracterización de los abordajes sofístico y filosófico de la política y, posteriormente, se describen ciertas perspectivas contemporáneas de conceptualización y acción política, con el propósito de señalar las coincidencias y paralelismos entre estas y los modelos clásicos sugeridos. Este ejercicio propende por analizar las consecuencias de la actualización que algunos autores contemporáneos han hecho, por un lado, del criterio relativista apropiado por la figura del sofista $y$, por otro, del juicio universalista adoptado por la contrafigura del filósofo, para evaluar la procedencia de una hipótesis según la cual el relativismo gestado en la tradición sofista tiene un lugar protagónico y dominante en la cultura política de nuestra época.

Palabras clave: política, relativismo, universalismo, sofista.

* Este artículo es el resultado de un proyecto monográfico de investigación adelantado a partir del mes de marzo del año 2019 en la Maestría en Filosofía Política que imparte la Facultad de Filosofía y Letras de la Universidad de Buenos Aires. El trabajo en cuestión fue desarrollado por el autor como requisito de aprobación del seminario en Filosofía Política Clásica impartido por los profesores Gabriel Livov y Pilar Spangenberg. Una versión acotada de los hallazgos del proyecto fue presentada por el autor a manera de ponencia académica durante el XIX Congreso Nacional de Filosofía Argentina (AFRA 2019), que tuvo lugar durante el mes de diciembre del año 2019, en la mesa temática titulada "Lecturas y resonancias contemporáneas de la filosofia política clásica: Aristóteles y la política". Citar como: Gutiérrez Lopera, R. E. (2020). Orígenes clásicos del relativismo politico contemporáneo. Cuadernos de Filosofía Latinoamericana, 41(123), 123-147. Dol: https://doi.org/10.15332/25005375/5702

* Estudiante de la Maestría en Filosofía Política de la Universidad de Buenos Aires, Argentina. Correo electrónico: esteban.gutierrez@usantotomas.edu.co 


\section{Classical Origins of Contemporary Political Relativism}

\section{Abstract}

This article characterizes the sophistic and philosophical approaches to politics and describes certain contemporary perspectives of political conceptualization and action, so as to point out their coincidences and parallels with the aforementioned classical models. The aim of this article is to analyze the implications of the efforts of some contemporary authors to bring up to date both the relativistic criterion associated with the figure of the sophist the universalist judgment associated to the counterfigure of the philosopher, so as to assess the hypothesis that relativism rooted the sophistic tradition holds a key and dominant place in the political culture of our time.

Keywords: Politics, Relativism, Universalism, Sophists.

\section{Introducción: perspectivas epistemológicas de la política}

La pregunta por el acceso al conocimiento es, probablemente, el registro donde se revelan más desiguales y contrastables los perfiles del sofista y del filósofo. De un lado, la teoría del conocimiento asociada al conjunto de pensadores agrupados bajo el rótulo de sofistas puede resumirse - sin reducirse - con el célebre lema protagórico que asume a la experiencia subjetiva del hombre como medida y límite de todo conocimiento posible de las cosas, lo cual sentencia la imposibilidad de que algo sea verdadero más allá del orden aparente de lo verdadero. Por el otro, el perfil del filósofo nos presenta un alegato que propende por hallar un fundamento en virtud del cual el conocimiento real de las cosas no se agotaría en sus meras expresiones perceptibles, sino que sería necesario un saber específico para conocer la esencia que subyace a lo aparente. De tal manera, mientras figuras como Protágoras o Gorgias entienden que el conocimiento está determinado por las condiciones formales y temporales del entorno en que alguien se formula una pregunta con la pretensión de conocer algo, Aristóteles 
y Platón no estarían muy dispuestos a conceder que las preguntas genuinamente filosóficas se contentan ante la ausencia de criterios universales e independientes a las circunstancias eficientes que orbitan a cada caso.

Teniendo en mente esta confrontación, es importante considerar que así como el sofista y el filósofo se introducen en una discusión clásica para dirimir la validez de sus ideas, en el contexto contemporáneo es posible apreciar una tensión similar entre dos perspectivas sobre el pensar y el quehacer político - que es el interés de este trabajo- que resultan, en un sentido conceptual antes que genealógico, herederas de los dos modelos epistemológicos referidos. La primera perspectiva, de carácter relativista, estaría representada por un conjunto de corrientes intelectuales a las que se les halla metodológicamente vinculadas con el campo interdisciplinar de los estudios culturales y filosóficamente familiarizadas con la faceta estructuralista de autores como Michel Foucault, Gilles Deleuze, Jacques Derrida o Roberto Espósito, entre otros, cuyo componente transversal es la asunción de una actitud mordaz de sospecha ante cualquier idea que aspire a ser exhaustivamente explicativa de la realidad, arguyendo que se estaría pasando por alto la importancia de estudiar los fenómenos - políticos o no- en su contexto de emergencia y bajo sus propias dinámicas operativas, semánticas, históricas, simbólicas, culturales, etcétera. En su dimensión política, este criterio relativista -que se resuelve aquí llamar "criterio" por cuanto no es en sí mismo una tradición o escuela de pensamiento, sino una característica que es común entre ellas- entiende que la acción política consiste en problematizar marcos prácticos e ideológicos en el orden de las circunstancias que los producen, lo cual deja en evidencia el lugar central que adquiere la particularidad cultural como capital de promoción de luchas políticas. Del otro lado estaría el modelo universalista, cuya representación se concede a la obra teórico-política de pensadores que advierten una supuesta dimensión universal de la política, como Jacques Rancière, Slavoj Žižek, Alain Badiou o Étienne Balibar. Esta concepción, que se afirma en contestación al relativismo político, defiende la idea de que la política es la actividad por la cual se movilizan valores capaces de erosionar prejuicios culturales particulares a efectos de rescatar derechos políticos universales, habida cuenta de que una actitud política, si se pretende genuina, no podría resignarse a recrear condiciones de vida justas en una comunidad particular que goza ella sola de los beneficios de la justicia, indistintamente de si en el contexto de una o varias comunidades diferentes la situación para sus miembros es completamente opuesta. En ese sentido, este criterio advierte que el despliegue político de ciertos derechos no habría de deprimirse a efectos de privilegiar el respeto y la tolerancia por lo culturalmente 
diferente. Con todo, este trabajo avanzará en el intento de explicar, mediante la exposición de los desacuerdos que caracterizan a la confrontación hasta aquí introducida, de qué manera el relativismo fundado en la tradición "sofista" deviene dominante frente al universalismo esgrimido por la tradición "filosófica” en lo que corresponde a su adopción como filosofía política del sentido común contemporáneo.

\section{Teeteto: sobre la medida relativa de todas las cosas}

La silueta del sofista nos es presentada por Platón como el contendiente intelectual más frecuente de las discusiones en las cuales se halla sumergido Sócrates, quien constituye el arquetipo cultural clásico del filósofo ateniense. A pesar del semblante crítico que el propio Platón sostiene respecto de los planteamientos de este antagonista del filósofo, en términos conceptuales no son menores ni particularmente injustos sus esfuerzos por recrear mediante diálogos el sistema conceptual que habría caracterizado al pensamiento de aquellos que, sin tenerse certeza historiográfica de que se designasen a sí mismos con la etiqueta, fueron agrupados en la historia de la filosofía occidental bajo la insignia de "sofistas". Protágoras, Gorgias, Sofista y Teeteto son algunos de los diálogos en los cuales es posible acceder a la caracterización que hace Platón de sus adversarios, entre cuyos rasgos generales más significativos, esbozados en la obra platónica, se encuentran su abordaje relativista de las cuestiones epistemológicas, por un lado, y una defensa conceptual de la técnica retórica, por otro.

Los elementos necesarios para abordar, inicialmente, la propuesta epistemológica del sofista se hallan contenidos en el Teeteto, diálogo cuyo objeto de debate es precisamente la naturaleza del conocimiento. Los participantes de la discusión son Teeteto, un joven ateniense que destaca entre los demás por su perspicacia e ingenio, su maestro Teodoro de Cirene, y, por supuesto, Sócrates, quien pone a prueba, a petición de Teodoro, las facultades que se predican del joven. Así, frente a la pregunta sobre qué es en realidad el saber, Teeteto introduce al objeto del diálogo arguyendo que no le parece que el saber sea otra cosa que percepción. Esta respuesta temprana invita a participar del debate a uno de los más célebres sofistas — si no el más-, Protágoras de Abdera, un interlocutor físicamente ausente, pero cuya presencia conceptual le hará el protagonista de la discusión de manera prolongada. De su vocería se hace cargo el propio Sócrates, quien inicia exponiendo los elementos que subyacen al razonamiento más comentado que se le atribuye a Protágoras y del cual la respuesta de Teeteto sería solamente una variante, a saber: "el hombre es medida de todas las cosas, tanto del 
ser de las que son, como del no ser de las que no son" (Teeteto 152a3-4; 1982, p. 147). El lema protagórico despierta tanto interés en la historia de la filosofía por proponer una medida insoslayable que condiciona no solamente al conocimiento de las cosas, sino al ser mismo de ellas: la subjetividad humana. De modo tal que nada adquiere estatuto de ser más allá de lo que aparenta ser ante quien lo percibe, por lo que el contenido de la percepción no es otra cosa que la expresión del ser y, por lo tanto, la única forma posible de conocimiento sobre la cosa. Entre otras, la forma que encuentra Sócrates para ejemplificar la equivalencia insinuada entre ser y parecer es recurrir al juicio que tendrían una persona sana y otra enferma al beber de una misma copa de vino, percibida como un trago dulce para la primera y amargo para la segunda, frente a lo cual sería una necedad decir que una de ellas está equivocada y no tiene conocimiento de lo que habla, mientras que la otra está en lo correcto y da cuenta de su sabiduría; pues el elemento percibido es el mismo y este no puede ser amargo, si es dulce, y viceversa. En realidad, lo que permitiría al vino ser dulce o amargo, se nos explica, es el referente de percepción y no el vino percibido en sí, de lo cual Sócrates concluye, cuidándose de asumir la lógica que habría de seguir Protágoras, que "ninguna cosa tiene un ser único en sí misma y por sí misma, sino que siempre llega a ser para alguien. Es más, el ser debería eliminarse en todos los casos”, pues solo es correcto hablar de lo que es en términos de lo que le parece a alguien que es (Teeteto 152d3-5; 1982, p. 145). En efecto, dado que todo ser es, en realidad, parecer, Protágoras establece la imposibilidad de ser y de conocer una naturaleza pura de la realidad, de lo que se sigue el sinsentido de distinguir categóricamente entre el conocimiento verdadero en sí y el que aparenta ser verdadero - un rasgo típico de la filosofía de Platón-, pues la verdad, en los términos relativistas que plantea el sofista, está asida por la subjetividad antropológica, con lo cual, "mi percepción — continúa Sócrates parafraseando a Protágoras- es verdadera para mí, pues es siempre de mi propio ser", de manera que "sigue siendo cierto así que yo soy juez [...] del ser de lo que es para mí y del no ser de lo que no es" (Teeteto 160c8-10; 1982, p. 149). De acuerdo con este razonamiento, el gesto relativista consiste, entonces, en reducir el ser, y con él a la verdad, a un proceso de construcción particular basado en mecanismos intrínsecos de juicio que descarta cualquier criterio que, pretendiéndose absoluto, sea empleado para referir a la cosa conocida, al sujeto que la conoce, o al conocimiento mismo que de allí deriva.

Dicho eso, conviene enunciar ciertas consecuencias que se siguen de abordar categorías políticas con las herramientas que ofrece este enfoque de pensamiento, propósito al cual también nos permite responder el Teeteto, a partir de que "en cuestiones 
políticas, lo honesto y lo deshonesto, lo justo y lo injusto, lo piadoso y lo impío, y cuanto cada ciudad determine y considere legal es así en verdad para ella" (Teeteto 167c5-7; 1982, p. 236), lo que circunscribe, como vemos, el alcance y la validez de los criterios políticos enunciados, particularmente la justicia, a los límites contextuales de cada comunidad política particular. A propósito de la distinción entre lo justo y lo injusto, Antifonte de Atenas - el sofista ateniense más importante del que se tenga noticia- también dedica una reflexión afín al criterio relativista según la cual alguien es justo solo en la medida en que no transgrede una norma o acuerdo vigente ante la mirada consciente de quienes la han convenido originalmente, pues la justicia que trae consigo la exigencia del cumplimiento de las leyes y los pactos no se deduce más que de la percepción colectiva, de modo que no hay en absoluto justicia o injusticia en aquellos actos que no son percibidos por los autores de la norma, dado que, a la manera de Protágoras, no hay ser sin percepción. "Por tanto —nos explica Antifonte-, al transgredir las normas legales, en la medida en que lo hacen sin conocimiento de aquellos que las han convenido, está libre de toda vergüenza y castigo" (Antifonte y Andócides, Fragmento DK в44 A Col. II; 1991, pp. 357-359). Este razonamiento se corresponde directamente con lo formulado por Protágoras, mediante Sócrates, al expresar que "lo que a cada ciudad le parece justo y recto, lo es, en efecto, para ella, en tanto lo juzgue así" (Teeteto 167c5-7; 1982, p. 236). En este sentido, del mismo modo que sucede con cualidades como lo dulce y lo amargo, lo frío y lo caluroso, lo bello y lo vulgar, solo con arreglo a una medida subjetiva, que para el caso político serían las consideraciones convencionales de una colectividad agrupada políticamente, es que tendría sentido hablar de valores como justicia, igualdad o libertad, por lo que el resultado de la tesis epistemológica de Protágoras en la política es el mismo que en otros ámbitos como el arte o la gastronomía. Las categorías políticas, su concepción, representación, realización y reclamo, quedan así adheridas a la subjetividad comunitaria, de lo que se sigue una renuncia a cualquier criterio universal de verdad en lo que a lo justo y lo injusto respecta.

Por otro lado, tal y como lo vimos con el ejemplo del vino, las opiniones falsas son un asunto contrafáctico, pues no es posible opinar falsamente sobre lo que no es, dado que nada es con independencia de su percepción, por lo que se da por supuesto que toda opinión es ya un conocimiento con funciones de verdad. No obstante, con esto Protágoras no quiere sugerir - ni Sócrates se lo reprocha- que todo aquel que guarde una opinión respecto de cualquier cosa merezca inmediatamente tratamiento de sabio o, por el contrario, que no hay entre la muchedumbre quienes destaquen por 
su sabiduría, pues nuestro sofista sí considera que unas disposiciones son "mejores" que otras, aun cuando no se las puede considerar más verdaderas. En defensa de Protágoras, Sócrates explica que la palabra "sabio" sirve "para designar a quien puede efectuar un cambio en alguno de nosotros, de tal manera que, en lugar de parecerle y ser para él lo malo, le parezca y sea lo bueno", pues que lo que separa a los sabios de los que no lo son es su capacidad para hacer de sus percepciones los pareceres del otro, y reemplazar en él la disposición ajena con la propia (Teeteto 166d9-11; 1982, p. 225). Mas este cambio no lo produce el sabio de cualquier manera, Platón introduce la siguiente característica de los sofistas (la práctica retórica) mediante una analogía también empleada por Gorgias de Leontinos - otro importante referente de la causa sofista- entre los efectos fisiológicos que tendría un fármaco en el cuerpo y los efectos persuasivos que tiene la palabra en la conciencia, advirtiendo que "mientras que el médico produce este cambio con drogas, el sofista lo hace mediante discursos" (Teeteto 167c9-11; 1982, pp. 225-226). Ciertamente, dado que, como hemos visto, la búsqueda de la verdad ha quedado clausurada como el fin al cual servirían las proposiciones de los sabios, el objetivo hacia el cual se proyectan los discursos enunciados por el sofista no es otro que la persuasión, un propósito que se consigue mediante composiciones argumentales que no distinguen entre conocimiento y opinión y a las que Platón se refiere como el arte de la disputa. En el ejercicio de la técnica retórica, la definición de categorías como "saber", por la que se preguntan Sócrates y Teeteto, se convierte en un recurso táctico que, antes que por su aproximación a la verdad, resulta valiosa por su aporte a la seducción discursiva que promovería el cambio hacia una disposición más "beneficiosa" - la propia-, todo lo cual desemboca rápidamente en un ambiente de exaltación de las propiedades estéticas del discurso por encima de sus pretensiones de verdad. Frente a la belleza de la retórica sofista la verdad del filósofo resulta secundaria, gratuita y poco persuasiva, al punto que incluso aquellos que se arrogan el membrete filosófico se ven arrinconados a comportarse, dice Sócrates, como "polemistas".

Para comprender el resultado histórico del abordaje retórico de la política, es preciso señalar el interés que expresaron los sofistas por advertir las propiedades del buen dominio del discurso como medida necesaria para alcanzar acuerdos políticos en el contexto de las ciudades-Estado griegas de los siglos v y IV a. C. y principalmente en la asamblea ateniense, a saber, enseñar el vínculo entre la técnica persuasiva del buen orador y la virtud política del buen ciudadano. En contravención a quienes consideraban que las competencias políticas se desprenden de una virtud que no le corresponde 
a cualquiera ostentar, como lo argüía el propio Platón, Protágoras defiende la tesis alegórica según la cual la capacidad política nos viene dada por merecimiento sobrenatural, entregada de la mano de Hermes como un regalo proveniente de Zeus, a todos por igual. No obstante, tal facultad política requeriría cultivarse y entrenarse para alcanzar eventualmente su mejor expresión, por lo que se harían necesarios mecanismos pedagógicos y comunicativos para aprenderla y enseñarla. Este afán por equiparar el uso de la palabra con la actividad política se corresponde con la necesidad de relacionar la figura del sofista con la actividad de la cual ellos se ocupaban y por la cual son recordados, célebremente por algunos y peyorativamente por otros, a saber: enseñar el arte de la argumentación y la persuasión a quienes tuvieran los recursos económicos para costearse sus servicios pedagógicos. En este orden de ideas, los sofistas no solamente ofrecían herramientas retóricas de seducción discursiva, sino que además prometían, en consecuencia, influencia política entre los miembros de la asamblea, un capital sumamente atractivo en el contexto de la deliberante democracia ateniense. Dicho en otras palabras, al enseñar la retórica, los sofistas enseñaban también la política, o un criterio relativo de esta - su criterio relativo-. El resultado, según se lo lamentan Platón y Aristóteles en sus disertaciones sobre lo que a su juicio era un síntoma de la decadencia ateniense, es una asamblea viciada por el abuso retórico de la palabra, una escena auspiciada por los aprendices de sofista, en la cual, por encima del objeto específico de las discusiones que allí tenían lugar, se superponían las formas mismas que servían de vehículo discursivo de la discusión, y hacían de los medios retóricos su propio fin. Así, la asociación entre discurso y política promovida por los sofistas acabaría recreando una suerte de "fetichismo de la técnica" — salvando todas las distancias conceptuales que la expresión implica- donde la estética del ejercicio discursivo era más valiosa que la postura conceptual asumida, puesto que aquellos que se revelaran más hábiles en el uso de la palabra conseguirían sus fines persuasivos tanto si estaban a favor como si estaban en contra de cualquier cuestión a debatir, lo que hacía justicia a la definición protagórica del saber y del sabio.

\section{La política o el universalismo político antiguo}

A continuación, revisaremos algunas de las objeciones que podrían formularse al modelo descrito sobe la base de los planteamientos que hace Aristóteles en la Política, su obra culmen sobre teoría política, y en otros textos, a partir de los cuales complementar la argumentación, como la Metafísica, la Ética a Nicómaco y los Analíticos segundos, e intentaremos rastrear las razones que motivan sus discrepancias con el 
acercamiento relativista, o directamente sofista, de la política, con el propósito de encontrar una propuesta que conduzca a resultados distintos.

Empezar, pues, recodando que el cuestionamiento que subyace a lo largo de la Política, heredado del cuestionamiento que ya se habría formulado Platón en el Político, es la posibilidad de hacer un abordaje científico de los aspectos asociados a la polis, pues "lo bueno y lo justo, sobre lo que realiza la política su indagación, presenta muchas diferencias e incertidumbres, de tal manera que parece existir por convención y no por naturaleza" (Ética a Nicómaco I, 3, 1094b; 2005, p. 49). Es en función de este problema que se pone a prueba la necesidad de un saber epistemológico que sea válido para pensar y hacer lo referente a la política, o si, tal y como lo afirma Protágoras, estas cuestiones encuentran indefectiblemente sus límites en la percepción de los miembros de una comunidad particular y de sus leyes convenidas. A este respecto, el filósofo apunta hacia el primer capítulo del cuarto libro que resulta "propio de una misma ciencia considerar teóricamente cuál es el mejor régimen político" (Política IV, 1, 1288b; 2015, p. 179). La respuesta, entonces, que calcula Aristóteles al interrogante inicial - adhiriendo nuevamente al diagnóstico de Platón- es que, en efecto, una concepción teórica específica sobre estos asuntos sería necesaria siempre que se aspire a saber qué es verdaderamente la política y cómo desempeñarse adecuadamente en lo que a ella concierne, dado que "debe poder determinarse teóricamente no solo cómo se constituye un régimen político desde el comienzo, sino también de qué modo, una vez constituido, podría preservarse por el mayor tiempo posible" (Política IV, 1, 1288b; 2015, pp. 179-180).

Cabe preguntar por las implicaciones que se siguen para Aristóteles de su pretensión de conocer un saber científico acerca de la disciplina política, para lo cual nos conviene remitirnos a la Ética a Nicómaco en el sentido de que "la ciencia es una concepción que versa sobre las cosas universales y las que son por necesidad" (Ética a Nicómaco vi, 5, 1140 b; 2005, p. 188). Siguiendo esta proposición, lo que fundamentaría propiamente a las categorías científicas, que son, a los efectos conceptuales del pensamiento aristotélico, las categorías filosóficas, sobre las cuales pretende constituir las bases de su estudio, es su pretensión de corresponder a la verdad universal de aquello acerca de lo cual se cuestionan, en este caso, la verdad de la política. El que la verdad sea, para el caso aristotélico, universal, reclama una explicación que nos permita distinguirla de su variante epistemológica sofista, y tal explicación es proporcionada por nuestro filósofo en los Analíticos segundos al sentenciar que atribuye el estatuto de "universal a lo que 
se da en cada uno en sí y en cuanto tal" (Analíticos segundos I, 4, 73b; 1995, p. 324). Tal definición, sustraída del contexto lógico de los Analíticos, parece no revelarnos inmediatamente mucho sobre lo que la universalidad supone para la política, pero constituye en verdad la definición aristotélica más completa, pues con ella se designan aquellos aspectos de algo (la política) cuya validez es tal que necesariamente se cumplen de manera transversal en cada una de las expresiones existentes y posibles de eso e indistintamente de sus especificidades. En otras palabras, aquel saber que es universal lo es por cuanto no se cumple solamente en ciertos casos, bajo ciertas condiciones o de acuerdo con ciertos criterios de percepción, sino que, si "todos los universales se dan por necesidad en las cosas", el saber universal ha de darse de manera absoluta e incontestable en cualquier grado de particularidad experimentable, porque respecto de sus vertientes en la experiencia es anterior y necesario (Analíticos segundos I, 4, 73b; 1995, p. 324).

Lo anterior se condice adecuadamente con un tópico recurrente de la filosofía aristotélica, subyacente en el método empleado a lo largo de la Metafísica y los Analíticos, a saber: la ciencia expresa la verdad de las cosas en la medida en que se remite a sus causas, pues estas, al ser condicionantes y anteriores, son dicientes sobre la naturaleza del objeto. Si se parte, como lo hace Aristóteles, de considerar que "siempre hay alguna naturaleza, sea una o más de una, a partir de la cual se genera lo demás, conservándose aquella", es posible deducir que preguntarse por las causas es preguntarse por un carácter absoluto y condicionante que permite y promueve todo lo relativo y condicionado, pues la naturaleza de algo es común a las múltiples y diferentes expresiones que se producen de eso en la experiencia (Metafísica I, 3, 983b; 1994, p. 81). Que la remisión a las causas es lo que distingue el conocimiento universal del relativo se corrobora al evaluar que, mientras en los Analíticos, por un lado, se designa "anteriores y más conocidas para nosotros a las cosas más cercanas a la sensación, y anteriores y más conocidas sin más a las más lejanas. Las más lejanas son las más universales, y las más cercanas, las singulares" (Analíticos segundos I, 2, 72a; 1995, p. 317); en la Metafísica, por el otro, se complementa el razonamiento al advertir que:

[...] el saberlo todo ha de darse necesariamente en quien posee en grado sumo la ciencia universal (este, en efecto, conoce en cierto modo todas las causas). $\mathrm{Y}$, sin duda, lo universal en grado sumo es también lo más difícil de conocer para los hombres (pues se encuentra máximamente alejado de las sensaciones). (Metafísica I, 2, 982a; 1994, p. 75) 
Asoma, pues, una discrepancia insalvable con el método sofista, según se expuso, dado que la verdad que se expresa a través del conocimiento estrictamente filosófico y científico es, para Aristóteles, una verdad esencial que no se reduce de ninguna manera a la singularidad de los casos que de ella derivan en la experiencia, dado que no es relativa a nuestras percepciones y sensaciones, y el contenido de ella misma — de la verdad universal - es, no obstante, la condición de posibilidad de todos ellos - los casos singulares-. Estas diferencias derivan en que, mientras el ejercicio de aproximación al objeto de conocimiento a través de la definición de las categorías que expresan sus causas es para el sofista un recurso meramente táctico y, en ese sentido, prescindible a los fines de la técnica retórica, para el filósofo constituye la unidad metodológica más básica de su actividad intelectual.

Así, la teoría política aristotélica, en la que, debido a la necesidad de explicar el método científico que el filósofo sigue, ni siquiera hemos reparado todavía, busca aproximarse a una comprensión sobre la política cuya medida de formulación y examinación no sea la subjetividad antropológica, tal y como sucede con el relativismo sofista, cuya verdad deriva de la percepción o, en su defecto, de la persuasión, sino un criterio válido universalmente. Con todo, dado que "la sabiduría es ciencia acerca de ciertos principios y causas", Aristóteles, intenta establecer un sistema científico de la política y no le queda otra opción más que remitirse a aquellos primeros principios, o causas, de su objeto de discusión (Metafísica I, 1, 982a; 1994, p. 74). A este respecto, se aporta un sentido concretamente científico y filosófico a la célebre sentencia según la cual "la ciudad-Estado se halla entre las cosas que existen por naturaleza y el ser humano es por naturaleza un animal político" (Política I, 2, 1253a; 2015, p. 66). Recordemos que, en términos del relativismo explicado por Platón, "si uno, al hablar, atribuye estabilidad a las cosas, se vería fácilmente refutado", pues el ser de las cosas se hace distinto y plural según los términos que condicionen a la percepción (Teeteto 157b; 1982, p. 205). No obstante, so pena de ser "fácilmente refutado" por aquellos para quienes "no existe sino lo que pueden agarrar con las manos" — dice Sócrates en el Teeteto, en el que podría ser interpretado como un tono burlesco-, cuando Aristóteles señala la anterioridad ontológica tanto de la ciudad-Estado como de la politicidad respecto del ser humano, premisa sobre la cual se funda toda una tradición filosófica de la política referida hasta nuestros días como naturalismo aristotélico, su intención no es otra que la de asentar principios científica y filosóficamente verdaderos, así como metodológicamente estables, que actúan como causas de la política por ser ellos la naturaleza universal que corresponde a toda comunidad e individuo, y se opone 
a una visión constructivista o convencionalista de la política (Teeteto 155e; 1982, p. 202). Asimismo, si la politicidad es necesaria respecto de la naturaleza humana, y en ese sentido es universal a ella, se desprende de esta premisa que, en relación con aquellos seres que se apartan de desplegar su vida con arreglo a los beneficios que permite la comunidad política, no ya por el desarrollo de los acontecimientos azarosos de su experiencia, sino porque su condición natural les hace autárquicos y no dependientes de ningún vínculo social o político, solo pueden ser definidos como seres inferiores (bestias) o superiores (dioses) al ser humano, puesto que a este le viene dado por naturaleza un defecto ontológicamente constitutivo que inhibe en él toda posibilidad de autosuficiencia.

Sentenciada la naturaleza social y política de la condición humana, en su ejercicio de avanzar por la vía que le dictan las causas, Aristóteles nos amplía el repertorio de causas y fines en lo que al desarrollo de la politicidad concierne, tal que así:

La comunidad perfecta conformada a partir de varias aldeas es la ciudad-Estado, de la cual puede decirse que alcanza ya el límite de autosuficiencia completa, en la medida en que surgió para la vida pero existe para la vida buena. Por eso toda ciudad-Estado existe por naturaleza, si también por naturaleza existen las primeras comunidades: puesto que la ciudad-Estado es el fin de aquellas, y la naturaleza es fin. (Política I, 2, 1252b; 2015, p. 66)

De este modo, la concatenación que se nos propone es que al ser humano le corresponde, por su naturaleza social, realizar su vida en una comunidad humana, cuya causa no es otra que la necesidad de garantizar la supervivencia de sus miembros, pero cuyo fin, dada esa misma naturaleza humana, que no es solamente social, sino que es fundamentalmente política, es el de convertirse en una comunidad política o ciudad-Estado, a la que, por la misma vía, le es propio el fin de conformar la comunidad perfecta mediante la generación de la vida buena de sus miembros. Así, pues, Aristóteles nos insinúa un tipo de fin, que al mismo tiempo es naturaleza y, en tal sentido, es causa final, el cual, si bien considerado en sus propiedades naturales, nos permitiría apreciar la dimensión universal ya no de la ciencia sin más, sino de la ciencia política, consistente en este bien supremo que ordena a priori todo régimen político existente y posible. Esta proposición se registra así en el análisis desde las disertaciones que introducen al libro primero, de acuerdo con las cuales: 
Puesto que vemos que toda ciudad-Estado es una cierta comunidad y que toda comunidad se constituye en busca de algún bien [...], resulta claro que todas las comunidades están orientadas hacia algún bien, y esencialmente hacia el supremo entre todos los bienes se orienta aquella que es suprema entre todas las comunidades y abarca a todas las otras. Esta es la que se llama ciudad-Estado y comunidad política. (Política I, 1, 1252a; 2015, p. 63)

Este bien supremo, cuyo contenido aún no conocemos del todo, pero a propósito del cual sabemos que es común y anterior a todas las comunidades, por un lado, y que, una vez alcanzado, permite a la comunidad devenir ella misma suprema, por el otro, es, además, la razón por la cual el Estagirita esgrime un criterio teorético que le permite distinguir insistentemente a lo largo de la obra entre los regímenes políticos correctos, en cuanto se corresponden con el bien supremo, y los desviados, en cuanto se apartan de él. Por lo que, si bien la causa final de la política es universal, y no puede sino serlo, las expresiones empíricas atestiguadas en los regímenes políticos históricos no están exentas de desempeñarse equivocadamente, lo cual, sin embargo, no desdice de su naturaleza y fin políticos.

Dicho esto, y "puesto que en todas las ciencias y técnicas el fin es un bien, en el más alto grado y principalmente lo será el de la suprema entre todas ellas: la disciplina política”, la causa final específicamente política no es otra que la justicia, y una que, desde luego, en contravención con lo dicho por Antifonte, no es relativa, sino absoluta (Política III, 12, 1282b; 2015, p. 160). De acuerdo con este criterio, el cual dispone que "el bien político es la justicia, la cual coincide con el interés común", en su explicación sobre los tipos de regímenes políticos posibles para una ciudad-Estado, Aristóteles nos advierte, considerando la relación que sostiene cada régimen con su causa final, que aquellos que se despliegan de acuerdo con lo que es bueno para todos y no solo para una de las partes de la ciudad, en la medida en que el interés común se integra al principio por el cual ellos fueron creados originalmente, "son correctos de acuerdo con un criterio absoluto de justicia, y todos aquellos que miran solo hacia la utilidad de los propios gobernantes son erróneos y constituyen desviaciones respecto de los regímenes correctos” (Política III, 6, 1279a; 2015, pp. 149-160). Así, por un lado, se expresa que el interés particular, sea el de un gobernante o el de cualquier otra de las partes singulares de la ciudad, toda vez que "alcanza un determinado aspecto de lo justo, pero solo avanza hasta cierto punto, sin expresar en su totalidad lo justo en sentido propio", no está en la capacidad de proporcionar el sentido absoluto que la justicia 
demanda, y, por el otro, se disiente de aquellos que "en lo justo y lo injusto, como en lo piadoso y lo impío, están dispuestos a afirmar que nada de esto tiene por naturaleza una realidad propia” (Política III, 9, 1280a; 2015, p. 152; Teeteto 172b; 1982, p. 236). Resulta altamente significativo señalar que, al distinguir entre regímenes rectos y desviados, que lo son por cuanto su realización coincide favorable o desfavorablemente con la causa final de toda ciudad-Estado (la vida buena que se sigue de una vida con arreglo a la justicia), Aristóteles apunta hacia aquellos que se despliegan de acuerdo con un criterio absoluto de justicia, y establece, en la Ética a Nicómaco, los términos en que se circunscribe este capital en su sistema teórico-científico, al considerar que "cada una de las normas justas y legales son como los universales en relación con los particulares: los actos que se realizan son muchos, pero solo no hay una de aquellas, pues es universal" (Ética a Nicómaco v, 7, 1135b; 2005, p. 169).

De conformidad con lo dicho, se reconoce, pues, un reclamo de universalidad en la filosofía política aristotélica con base en el cual a todo sistema político existente y posible le corresponde la realización de un criterio de justicia válido universalmente, que garantice la vida buena para cada una de las partes de la comunidad política y que lo haga indistintamente de las particularidades y singularidades de las que su lugar en la ciudad nos informa. La justicia a la que se refiere nuestro filósofo no se deduce, entonces, de las convenciones, pues está ligada directamente con la causa final de la ciudad-Estado, y es, por tanto, universal y común a cualquiera de sus expresiones históricas.

Es importante destacar, por otra parte, que el conjunto de cuestiones referidas en este apartado no se inscribe en el registro de la genealogía política, la pretensión de Aristóteles no se agota en el estudio de la evolución histórica de los sistemas políticos, y así lo establece él mismo al señalar que, "en qué hay igualdad y en qué hay desigualdad es una cuestión que no debe dejarse de lado: pues esto encierra una dificultad y reclama una filosofía política" (Política III, 12, 1282b; 2015, p. 160). Dado que una reflexión sobre principios políticos, como es el caso de la justicia, implica la dificultad de conocer las causas finales que remiten a su naturaleza, pensar la política demanda ir más allá de las medidas relativas y las convenciones culturales, pues la ciencia política requiere perspectivas universales. Aristóteles, entonces, al señalar que "los hombres de experiencia saben el hecho, pero no el porqué, mientras que los otros conocen el porqué, la causa", no podría sino acabar descartando a los sofistas por su incapacidad para enseñar nada que no sean sus propias opiniones empíricamente formadas, 
pues al no saber nada que trascienda a lo que consideran ellos mismos que es el saber, no saben tampoco qué es la política, ni requieren saberlo para desempeñarse con éxito en su labor de enseñanza de la técnica retórica (Metafísica I, 1, 981a; 1994, p. 72). Afrontar la política esgrimiendo la filosofía de Aristóteles conduce, en este sentido, a declarar la incompatibilidad entre la propuesta relativista del sofista y las condiciones que, según el ateniense, exige la política para ser entendida.

\section{Posmodernidad o actualización del relativismo político}

De acuerdo con lo propuesto, lo que corresponde ahora es explorar la forma en que ciertos aspectos pertenecientes a los dos modelos de la filosofía clásica descritos resultan actualizarse mediante algunas de las expresiones teóricas y prácticas de la política contemporánea, ya sea por herencia conceptual, por inspiración filosófica o por mera coincidencia histórica. Para tal propósito nos conviene empezar por enunciar que, de unas décadas hacia la actualidad, se ha venido acuñando el término “posmodernidad" para designar el capítulo de la historia al que atendemos y de cuya matriz ideológica somos culturalmente deudores, por lo que saber a qué nos referimos cuando hablamos de posmodernidad es requisito para reconocer algunos de los patrones de la cultura política contemporánea. Así, en un intento de esbozar de manera general los rasgos que constituirían la identidad de la posmodernidad, ubicaremos al menos tres marcos de referencia cuya presencia en el panorama actual es decisiva, e insinuaremos el tipo de función que cumple cada marco referencial a efectos de dirimir, en primer término, qué tanto del criterio relativista hay en las formas de la cultura política posmoderna.

Dicho lo anterior, el primer marco sugerido aportaría un referente descriptivo de las lógicas culturales actuales, función reconocible en obras escritas tan célebres como La condición posmoderna (1979), donde el filósofo francés Jean-François Lyotard expone la situación de devaluación padecida por los cuatro "metarrelatos" con aspiraciones universales de emancipación que antaño configuraban el horizonte discursivo de la Modernidad, a saber: el marxismo, el cristianismo, la ilustración y el capitalismo. Ante el lugar vacío que se abría con la decadencia de los pilares del proyecto ideológico moderno, el diagnóstico del autor no consiste en señalar un nuevo modelo de proporciones semejantes y propiedades alternativas al saliente, sino en fragmentar la mirada y oponer a los desgastados anhelos universales una novedosa lógica de acción local y descentralizada que encuentra en las “micronarrativas" el combustible necesario para 
gestionar cambios concretos en los entornos particulares donde se requieran. Por una vía similar van las consideraciones sociológicas de Zygmunt Bauman, las cuales se recogen sobre la insistente y afamada metáfora de la "liquidez", que propone una fotografía del estado informe, inaprehensible e indiscernible que asumen las seudoestructuras sociales actuales; amor líquido, miedo líquido, vigilancia líquida, maldad líquida, vida líquida, tiempos líquidos, mundo líquido, son algunos de los informes reflexivos que ofrece Bauman para exhibir las condiciones de una modernidad líquida —o posmodernidad - donde nada tiene un ser, saber o sentido acabado, y cada aspecto de la vida es construible y deconstruible según sus medidas relativas de existencia.

El segundo marco de referencia cumple la función de aportarle a la posmodernidad un complejo y bien constituido sistema conceptual sobre el cual fundamentarse filosóficamente, situado en las proposiciones estructuralistas de pensadores de la talla de Michel Foucault y Gilles Deleuze, cuyos estudios y debates, ampliamente conocidos, alrededor de los conceptos de saber, poder y subjetivación ostentan un protagonismo especial en el repertorio discursivo que los nuevos movimientos sociales esgrimen para dotar de consistencia conceptual a sus luchas políticas. El componente enfático de esta corriente es la idea de que la subjetividad solo tiene lugar como el producto accidental de las pugnas históricas entre estructuras de saber y de poder, de lo cual se sigue, consecuentemente, un desencanto por cualquier idea que tenga la pretensión de afirmarse por fuera de los procesos de construcción histórica, algunas de las cuales ya hemos mencionado, como lo absoluto, la naturaleza y la universalidad. En su lugar, estos pensadores centran su atención en las denominadas "posiciones del sujeto", asumiendo la premisa de que nada dentro de lo perceptible, pensable o decible escapa al registro de la historicidad, y la condición humana no es la excepción, pues no puede ser entendida independiente de los dispositivos históricos que condicionan su subjetividad, de manera que cualquier verdad que sobre ella sea dicha no escapa al orden contextual del discurso que la produce.

Finalmente, el tercer marco de referencia, en buena parte gestado desde el campo de los estudios culturales, cumple una función metodológicamente propositiva en la medida en que designa un nuevo lugar de disputa política al superponer las identidades diversas y el multiculturalismo sobre toda lógica de acción o enunciación política. En una conversación entre Miguel Mellino y Stuart Hall, este último - uno de los mayores exponentes de este campo- explica que la acción solo es política cuando asume discusiones en torno al poder, y que, por otro lado, los estudios culturales solo 
lo son si aguardan la intención de desenmascarar la relación que hay entre la cultura y el poder, de lo cual se deduce la necesidad que tienen los estudios culturales de referirse a la política. Su reflexión se complementa al indicar que:

[...] si aceptamos la índole conjetural del campo de los estudios culturales, resulta difícil pensar que la relación entre cultura y poder sería la misma en la Argentina y en Gran Bretaña. ¡Esto es imposible! Por ello, puede afirmarse que todos hacemos estudios culturales solo en el sentido de que - en relación con nuestra propia situación histórica específica y dentro de las tradiciones intelectuales en que nos hemos formado- en nuestros análisis examinamos los modos merced a los cuales la cultura y el poder obran actualmente en nuestras sociedades. (Hall y Mellino, 2007, pp. 15-16)

Este orden de los factores tiene gran correspondencia con lo planteado por el filósofo canadiense Charles Taylor a propósito de lo que denominó casi hegelianamente "política del reconocimiento", según la cual las corrientes políticas contemporáneas se organizan, justamente, en torno a la necesidad de reconocimiento de su particularidad cultural; esta "exigencia aparece en primer plano, de muchas maneras, en la política actual, formulada en nombre de los grupos minoritarios o 'subalternos', en algunas formas de feminismo y en lo que hoy se denomina la política del 'multiculturalismo"” (Taylor, 2009, p. 53). De esta manera, el eje en torno al cual trabajan las reflexiones tanto de Hall como de Taylor es la reivindicación de la diferencia cultural de los sectores políticamente movilizados.

A propósito de los paralelismos entre el criterio relativista procedente del registro sofista antiguo y las discusiones contemporáneas sobre la política, interesa subrayar un par de ideas que resultan sugestivas para identificar la predominancia del relativismo en el debate vigente. En primer lugar, al igual que Protágoras tuvo a bien reducir los aspectos cognoscibles de la realidad a la percepción humana, las lógicas sociales posmodernas han retomado el gesto y lo han ajustado de tal manera que ni la condición humana quede librada de ser relativa, al poner sobre la mesa la que en la actualidad pasa a ser la nueva "medida de todas las cosas": la sujeción histórica y cultural. Así, pues, el relativismo contemporáneo introduce a la propia subjetividad antropológica en el saco de lo relativo, y señala que hasta la medida indicada por Protágoras es una construcción dependiente de las circunstancias culturales que tengan lugar en determinado momento de la historia. En las condiciones actuales de debate conceptual, 
regidas por un sistema semejante, tratar de abordar filosóficamente aspectos como la "naturaleza humana", como en su momento lo pretendió Aristóteles, se convierte en una suerte de gran despropósito, puesto que cualquier intento de referenciar una naturaleza está ya inmediatamente cercenado por la lógica que dicta que todo lo que es lo es en cuanto que ha sido construido así en la experiencia y no por un principio intrínseco ontológicamente inalterable, con lo cual, no hay tal cosa como una naturaleza humana, si por ella se entiende un criterio universal de lo humano. Por otra parte, dado que llevar el relativismo hasta sus últimas consecuencias implica afirmar que el ser de las cosas, en rigor, no depende en absoluto de ellas, al punto en que se hace imposible que algo exista por fuera de las convenciones sociales, se recrea en la actualidad un filtro "posideológico" — término empleado por Slavoj Žižek- que inhibe a cualquier categoría de ser plenamente compatible con un contexto distinto al que le dio cabida originalmente, pues el espectro se torna tan difuso, heterogéneo y líquido -o esquizofrénico, en palabras de Gilles Deleuze y Félix Guattari-que ninguna afirmación puede ser entendida de la misma manera, si los parámetros de referencia son distintos de aquellos que la produjeron en principio. Las condiciones de inestabilidad conceptual son tales que, recordando lo dicho por Sócrates en el Teeteto, atribuir estabilidad a algo, por ejemplo, esgrimir la formulación política de una justicia absoluta, es exponerse a ser fácilmente refutado.

En efecto, uno de los resultados políticos más evidentes de la actualización del relativismo en la posmodernidad es que la diferencia cultural adquiere estatuto de derecho político por encima de cualquier otro valor, de manera tal que la particularidad, sea esta del tipo que sea, comparte ahora la condición de medio y fin de las causas políticas. Por otra parte, conviene tener en cuenta que aquellas luchas que se promueven mediante esta lógica solamente tienen validez y sentido para los miembros de aquellas comunidades que las vieron originarse, y las iniciativas que propendan por exportar valores y derechos políticos más allá de las fronteras que representan las diferencias culturales corren irreparablemente el riesgo de ser severamente juzgadas por entrar en un terreno asociado con valores muy poco atractivos como el extremismo, la intolerancia, el absolutismo, la imposición y la violencia, ámbitos sobre los cuales se suele decir que representan, de hecho, negaciones de la política. Dado lo anterior, valores como la tolerancia, el pluralismo y el respeto por la diferencia acaban convirtiéndose en los principios de la acción política por excelencia, de allí que el multiculturalismo, según lo entiende Taylor, devenga reducido precisamente a recordarnos cuáles son los límites y las distancias que han de ser socialmente reconocidas y culturalmente 
conservadas para no anular ninguna dimensión posible de la singularidad, aun si ella es una singularidad en condiciones de dominación injustas y desiguales, pues su valor político no deriva de las calidades del lugar que ocupa en el registro multicultural, sino del hecho efectivo de que formalmente ocupa un lugar particular y diferente respecto de todos los demás. En otras palabras, tal y como Taylor lo entiende, la defensa de la particularidad es el nuevo propósito al que sirve la acción política, y la política "se transforma en una batalla cultural por el reconocimiento de las identidades marginales y por la tolerancia con las diferencias” (Žižek, 2008, p. 59).

\section{El alegato universalista contemporáneo}

Buena parte de los tópicos tradicionales de la filosofía política se formulan en oposición a un modelo vigente y estable en un momento puntual de la historia, y así lo hace también la obra del filósofo esloveno Slavoj Žižek, quien estructura su teoría política como respuesta a aquellos discursos y prácticas que desempeñan su activismo esgrimiendo el criterio relativista. En uno de sus textos más comentados de los últimos años, En defensa de la intolerancia (1998), el autor busca advertir, precisamente, sobre los escenarios que se pasan por alto al disponer el reconocimiento identitario multiculturalista en el centro de las exigencias de los movimientos políticos contemporáneos. Al rechazar cualquier tipo de incidencia que trastorne la subjetividad de aquellas individualidades o colectividades cuyas manifestaciones identitarias son de una dignidad tal que no podrían sino enriquecer la idea de un escenario en el que es posible gozar de la experiencia de la pluralidad en el encuentro con el Otro, mientras expresamos el sentido propio de nuestra identidad sin temor a ser violentados por repertorios de discriminación o intolerancia, el multiculturalismo político, al que el filósofo califica como la demostración de una homogenización sin precedentes, tiende a equiparar diferencia con desigualdad o, lo que es igual, a legitimar la desigualdad en virtud de la diferencia. Esto es así, plantea Žižek, pues al disponer la diferencia cultural como el objeto medular de la acción política, se suelen confundir dos planos referenciales drásticamente distintos, a saber:

Por un lado, el licenciado universitario cosmopolita de clase alta o media-alta, armado oportunamente del visado que le permite cruzar fronteras y "disfrutar de la diferencia"; del otro, el trabajador pobre (in)migrante, expulsado de su país por la pobreza o la violencia y para el cual la elogiada "naturaleza híbrida" supone una experiencia sin duda traumática, la de no llegar a radicarse en un 
lugar y poder legalizar su estatus, que actos tan sencillos como cruzar una frontera o reunirse con su familia se convierten en experiencias angustiosas que exigen enormes sacrificios. Decirle a este sujeto que debería disfrutar de lo híbrido, decirle que su existencia es en sí misma migrante, que nunca es idéntica a sí misma, etc., es de un cinismo semejante al de la exaltación de Deleuze y Guattari del sujeto esquizoide. (Žižek, 2008, p. 62)

La situación descrita muestra cómo somos invitados a experimentar las injusticias estructurales como si se tratara de diferencias culturales, un escenario donde el subtexto de la tolerancia abandona toda imposición de valores justos y represión de los injustos, puesto que la justicia es un efecto de las convenciones, como explican Protágoras y Antifonte, y no un margen universal, como quisiera Aristóteles. La razón de esto es que el valor de la justicia, antecedido por el juicio historicista que lo reduce a una expresión relativa de las circunstancias socioculturales, se ve constreñido y a discreción de lo que dicte el constructivismo, en razón de lo cual todo criterio de justicia se define por aquello que cada comunidad particular convenga culturalmente que es justo e injusto para el interés y beneficio de ella misma, sin plantearse la posibilidad de un modelo de justicia que opere de manera universal y con el cual se estaría entrando en contradicción. Este desplazamiento de la justicia hacia el saco de la relatividad, por un lado, permite descartar con cierta ligereza cualquier pretensión de reprochar injusticias desde la exterioridad del contexto histórico en el cual esta injusticia se produce, y por el otro, contribuye a la naturalización y legitimación de expresiones claras de injusticia en contextos culturales diferenciados bajo el entendido de que lo que en un contexto específico es percibido como injusto, puede adquirir un sentido distinto bajo la cosmovisión imperante en otro contexto, al confundir la injusticia social con la diferencia cultural y legitimar la primera en favor y exaltación de la segunda. De este modo, el diagnóstico que nos ofrece el esloveno es que el planteamiento tolerante del multiculturalismo, que pone el énfasis en la politización de las luchas por la diferencia cultural y celebra su proceso de "hibridación", no solamente da la espalda al problema que supone la homogeneidad de un sistema de dominación económica mundial, sino que además, por la misma vía, elude la pregunta que, a juicio de Žižek, contiene el problema decisivo de los tiempos que corren y que consiste en “¿cómo reinventar el espacio político en las actuales condiciones de globalización?” (Žižek, 2008, p. 63).

"La prensa liberal nos bombardea a diario con la idea de que el mayor peligro de nuestra época es el fundamentalismo intolerante, [...] y que el único modo de resistir 
y poder derrotarlo consistiría en asumir una posición multicultural" (Žižek, 2008, p. 11), y las propuestas de autores como Žižek y Jacques Rancière se cuestionan si este planteamiento contiene realmente un problema de carácter político o si es, más bien, un falso dilema cuyo discurso está, de hecho, despolitizado. En efecto, estos pensadores estriban sus argumentos en cierto supuesto que, considerando su origen, podríamos identificarlo como de orden aristotélico, según el cual la "verdadera política" tiene, por defecto, una irrenunciable dimensión de universalidad, sin la cual se hace imposible entablar discusiones o promulgar consignas que nos lleven a las consecuencias de la dignidad que la política exige. En ese sentido, el reclamo consiste en afirmar que se eleva en torno a los términos políticos actuales un montaje "pospolítico" que Žižek atribuye al multiculturalismo posmoderno, y en razón del cual se elimina la universalidad política, y se sacrifica, con esta, a la política misma. Tanto para Žižek como para Rancière, la latencia política es un fenómeno que remite a la condición universal de igualdad y libertad que padece el género humano en su inmensa heterogeneidad, y a pesar de ella, esto es, una naturaleza que determina a los seres humanos como iguales y libres a todos los efectos. Referida por Étienne Balibar como el principio de igualibertad, este capital inalienable constituye un tipo de verdad que, a partir del momento de su enunciación, es válida en cualquier circunstancia histórica o cultural para impugnar cualquier expresión de injusticia allí donde ella se presente; verdad según la cual todos los seres humanos somos iguales entre sí en cuanto seres dotados de palabra. De tal modo, explica Žižek, lo verdaderamente político es:

[...] un fenómeno que apareció, por primera vez, en la Antigua Grecia, cuando los pertenecientes al demos no solo exigieron que su voz se oyera frente a los gobernantes, [...] sino que, ellos, los excluidos, los que no tenían ningún lugar fijo en el entramado social, se postularon como los representantes, los portavoces, de la sociedad en su conjunto, de la verdadera Universalidad ("nosotros, la 'nada' que no cuenta en el orden social, somos el pueblo y todos juntos nos oponemos a los que solo defienden sus propios intereses y privilegios"). (Žižek, 2008, pp. 25-26)

Tal nosotros, ciertamente, no refiere a una colectividad cultural que se arrogue la necesidad de reconocimiento sobre su singularidad como germen de lo político, sino que su situación política es concebida recurrentemente por estos pensadores como una parte que, sin tener un lugar específico en el recuadro sociopolítico, sostiene entero al recuadro mismo. Este es un nosotros que, dado que ha sido desprovisto de 
un lugar específico en la estructura afín de que en ella se mantenga un régimen de particularidades diferenciadas, solo le es posible aferrarse al único principio que le queda para enunciar su situación política: la igualibertad. Esto es, tal apelación no está dirigida, como sucede en la política del reconocimiento, a reclamar el valor que subyace a la identidad cultural de la que se es usuario en cuanto que sujeto histórico, pues quien lo reclama lo hace porque no tiene ya singularidad cultural de la cual servirse, sino que propende por un principio que nos informe de su condición humana en cuanto que sujeto trascendental, y que no habría sido reclamado para sí por las partes de la estructura por no ser este principio un valor cultural particular, sino la condición humana universal. Dado que el reclamo de la igualibertad no lo promueve la parte para sí misma (soy un ser humano), sino que a través de él pretende emancipar a la estructura misma de su prejuicio particularista (somos todos seres humanos), en virtud de este reclamo se sigue que el rechazo a la injusticia que acarrea la enajenación de la igualibertad no puede fragmentarse por la heterogeneidad cultural, dado que la injusticia misma no está fragmentada cuando enajena este principio, y esto lo determinaría como un nosotros genuinamente político y universal. Vemos, entonces, que Žižek propende por distinguir dos planos que en el criterio relativista aparecen confundidos, esto es, la situación cultural del sujeto y su situación política. Esta misma distinción es la que permitiría distinguir entre diferencia y desigualdad, esta última es una desproporción tal que no da lugar a matices, ambigüedades, porosidades o escalas de grises, y en razón de la cual se revela su carácter de independiente de la especificidad cultural, económica, sexual, racial, etcétera.

Rancière, por su parte, deviene igualmente usuario de estas distinciones en su filosofía política, y refuerza el planteamiento de la dimensión universal al argüir que:

Hay orden en la sociedad porque unos mandan y otros obedecen. Pero para obedecer una orden se requieren al menos dos cosas: hay que comprenderla y hay que comprender que hay que obedecerla. Y para hacer eso, ya es preciso ser igual a quien nos manda. Es esta igualdad la que carcome todo orden natural. [...] En última instancia, la desigualdad solo es posible por la igualdad. Hay política cuando la lógica supuestamente natural de la dominación es atravesada por el efecto de esta igualdad. [...] Solo hay política cuando esas maquinarias son interrumpidas por el efecto de un supuesto que les es completamente ajeno y sin el cual, sin embargo, en última instancia ninguna de ellas podría 
funcionar: el supuesto de la igualdad de cualquiera con cualquiera. (Rancière, 1996, pp. 31-32)

En estos términos, cualquier negación de la igualdad, independientemente del contexto, lugar y época en que se produzca, constituye inmediatamente una negación de tipo universal, de lo cual se entiende que, para los "sin parte", el problema no es el atentado contra su identidad cultural, sino que está anclado a los repertorios de desigualdad reproducidos por un modelo de sociedad que, cuando es injusto, en cualquier sentido y aunque se nos presente atomizado y disgregado por la heterogeneidad de los contextos, es universalmente injusto. En este sentido, la propuesta teórica en cuestión está encaminada a formular que la necesidad de organizarse en torno a fundamentos y estructuras políticas no se deduce del mero reconocimiento de la diferencia del Otro, sino que implica erosionar esa diferencia para ocuparse de las circunstancias que son comúnmente conflictivas, y promover cierta conciencia transversal de la política que emerge "cuando descubro que el atolladero en el que estoy es también el atolladero en el que está el Otro" (Žižek, 2008, p. 61). A este respecto, Rancière plantea un paralelismo entre la institución de la política y la institución de la lucha de clases para delatar que se trata de registros en verdad idénticos, bajo la salvedad de que la política no aparece por el hecho de que un grupo social como el proletariado entre en disputa con otros por efecto de sus intereses divergentes; en realidad, la analogía busca apuntar que "el proletariado no es una clase sino la dislocación de todas las clases, y en eso consiste su universalidad" (Rancière, 1996, p. 33).

Cabe preguntarse si a la particularidad, en su sentido conceptual más laxo, le queda o no un lugar, considerando que no parece acabar de aportar nada en una formulación que postula a la universalización como el gesto político por excelencia. Lo cierto es que ni Žižek ni Rancière abogan en sus modelos teóricos por negar el vínculo entre la particularidad y la política — no más allá de señalar, mediante un rodeo genuinamente hegeliano, que dicho vínculo o articulación entre lo universal y lo particular no es el que la posmodernidad pretende que sea-, y esto se evidencia en el reconocimiento que hace el esloveno de lo que llama un "cortocircuito" entre lo universal y lo particular, al referirse a un presupuesto que, a su juicio, es incondicional con lo que llama la verdadera política, según el cual el agenciamiento del propósito universal solo puede ser encargado a la particularidad desconectada y desubicada, que se presenta como encarnación de la universalidad. El autor francés, por su parte, nombra a esta disposición de los conceptos la universalidad singular, y explica que su 
aparición consiste en apelar a esa parte que ha sido sustraída de un lugar en el orden social y que, a su vez, apela a la universalidad no para emanciparse a sí misma sino para emancipar a la estructura entera, en esta Rancière espera encontrar un medio plausible para la consecución de un fin con proyección universal. No obstante - $y$ aquí radica la distinción entre celebrar la diferencia por sí misma, o extraer de ella su valor político sin sacrificar la política en el proceso-, ningún medio puede ser su propio fin, si de él se espera deducir algo distinto del medio mismo. Dicho en otras palabras, no tendría sentido, en el rigor del planteamiento que se nos sugiere, encontrar en el hecho de las subjetividades diversas el fin político de nuestra propia condición divergente, como quien designa el reconocimiento y la conservación de las identidades dominadas como propósito de las causas políticas de los dominados. Solo si esto es así la parte enajenada del conflicto puede erguirse para oponerse a aquellos cuyo único interés es la defensa de sus propios privilegios particulares, de los cuales gozan, vale reiterar, debido a que las desigualdades estructurales estriban en la defensa de las diferencias contextuales. Esta forma de instituir la política no se consigue al hacer de un hecho como la particularidad étnica, sexual, histórica, religiosa, etcétera, el derecho político primordial; sino que se construye reconciliándose con una medida que no es relativa, reductible o enajenable: el supuesto universal de igualdad de cualquiera con cualquiera.

\section{Referencias}

Antifonte y Andócides. (1991). Fragmentos y discurso (J. Redondo Sánchez, trad.). Madrid: Gredos.

Aristóteles. (1994). Metafísica (T. Calco Martínez, trad.). Madrid: Gredos.

Aristóteles. (1995). Tratados de lógica (Órganon) vol. II: Segundos analíticos (M. Candel Sanmartín, trad.). Madrid: Gredos.

Aristóteles. (2005). Ética a Nicómaco (J. Calvo Martínez, trad.). Madrid: Alianza.

Aristóteles. (2015). Política (G. Livov, trad.). Buenos Aires: Universidad Nacional de Quilmes, Prometeo.

Balibar, É. (2017). La igualibertad. Barcelona: Herder. 
Foucault, M. (2006). Seguridad, territorio, población. Curso en el College de France (1977-1978). Buenos Aires: Fondo de Cultura Económica.

Hall, S. y Mellino, M. (2007). La cultura y el poder. Conversaciones sobre los cultural studies. Buenos Aires, Madrid: Amorrortu.

Lyotard, J. (1991). La condición posmoderna. Informe sobre el saber (M. Antolín Rato, trad.). Madrid: Editions de Minuit.

Platón. (1982). Diálogos V: Teeteto (I. Santa Cruz, Á. Vallejo Campos y N. L. Coredero, trads.). Madrid: Gredos.

Rancière, J. (1996). El desacuerdo. Política y filosofía. Buenos Aires: Nueva Visión.

Taylor, C. (2009). El multiculturalismo y "la política del reconocimiento" (M. Utrilla de Neira, L. Andrade Llanas y G. Vilar Roca, trads.). Ciudad de México: Fondo de Cultura Económica.

Žižek, S. (2008). En defensa de la intolerancia. Madrid: Sequitur.

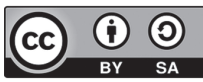

